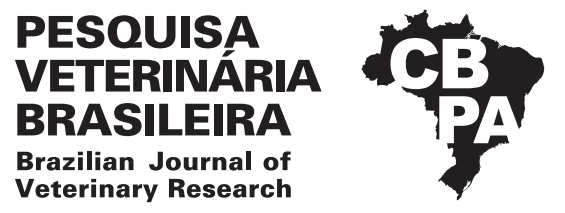

Pesq. Vet. Bras. 39(8):635-642, August 2019 DOI: 10.1590/1678-5150-PVB-6264

Original Article

ISSN 0100-736X (Print)

ISSN 1678-5150 (Online)

\title{
Prognostic value of coupling interval, prematurity index and heart rate variability in Boxer $\operatorname{dogs}^{1}$
}

\author{
Elizabeth Regina Carvalho ${ }^{*}$ (D), Evandro Zacché2, Michelli Fenerich², \\ Aparecido Antônio Camacho ${ }^{2}$ and Marlos G. Sousa ${ }^{3}$
}

\begin{abstract}
Carvalho E.R., Zacché E., Fenerich M., Camacho A.A. \& Sousa M.G. 2019. Prognostic value of coupling interval, prematurity index and heart rate variability in Boxer dogs. Pesquisa Veterinária Brasileira 39(8):635-642. Faculdade de Medicina Veterinária e Ciências Agrárias, Universidade Estadual Paulista, Via de Acesso Prof. Paulo Donato Castellane s/n, Jaboticabal, SP 14884-900, Brazil. E-mail: beth_rcarvalho@hotmail.com

Boxer dogs with arrhythmogenic right ventricular cardiomyopathy (ARVC) can experience sudden cardiac death regardless of presence/absence of clinical signs. The aims of this retrospective study were two-fold: 1 ) to investigate the coupling interval (CI) and prematurity index (PI) of ventricular arrhythmias (VA), and the heart rate variability (HRV) in Boxers, and 2) to evaluate their impact on overall survival time. The first 24-hour Holter 36 client-owned Boxer dogs meeting inclusion/exclusion criteria were evaluated for the number, morphology, site of origin, complexity, CI and PI, of ventricular premature complexes (VPCs), and time domain HRV. The effect on survival was assessed, considering the presence/absence of ventricular tachycardia (VT), and syncope. All-cause mortality was considered as the end-point, with median survival times being obtained by Kaplan-Meier analyses and compared by log-rank test. Polymorphic VPCs were more common in symptomatic dogs than asymptomatic. VPCs in dogs with VT were less premature, due to the influence of heart rate on PI despite comparable CI. The PI and mean heart rate (HRme) were significantly different between VT and non-VT dogs but did not discriminate adequately between groups as standalone tests. Median survival time was shorter in Boxer dogs with VT (463 vs 1645 days, HR: 4.31, P=0.03). The HRV parameters, SDNN and SDANN, were both associated with prognosis. The CI and PI were not demonstrated to be prognostic surrogates in Boxer dogs with VA. HRme $\geq 112 \mathrm{bpm}$ is $100 \%$ sensitive but only $46 \%$ specific for detecting VT in Boxers on the 24 -hour Holter. Presence of VT, SDNN $\leq 245 \mathrm{~ms}$, or SDANN $\leq 134 \mathrm{~ms}$ at the time of the first 24-hour Holter was associated with a shorter survival.
\end{abstract}

INDEX TERMS: Prognostic, coupling interval, prematurity index, heart rate, Boxer dogs, arrhythmias, sympathetic nervous system, sudden death, dogs.

RESUMO.- [Valor prognóstico do intervalo de acoplamento, índice de prematuridade e variabilidade da frequência cardíaca em cães da raça Boxer.] Cães da raça Boxer com cardiomiopatia arritmogênica do ventrículo direito (CAVD) podem apresentar morte súbita independentemente da presença/ausência de sinais clínicos. Os objetivos desse estudo retrospectivo foram: 1 ) investigar o intervalo de

\footnotetext{
${ }^{1}$ Received on January 22, 2019.

Accepted for publication on April 1, 2019.

${ }^{2}$ Faculdade de Medicina Veterinária e Ciências Agrárias, Universidade Estadual Paulista (Unesp), Via de Acesso Prof. Paulo Donato Castellane s/n, Jaboticabal, SP 14884-900, Brazil. *Corresponding author: beth_rcarvalho@hotmail.com

${ }^{3}$ Laboratório de Cardiologia Comparativa, Universidade Federal do Paraná (UFPR), Rua dos Funcionários 1540, Curitiba, PR 80035-050, Brazil.
}

acoplamento (IA) e o índice de prematuridade (IP) das arritmias ventriculares e a variabilidade da frequência cardíaca (VFC) em Boxers, e 2) avaliar o impacto de tais características sob o tempo de sobrevida global. 0 primeiro Holter de 24 horas de 36 Boxers selecionados para os critérios de inclusão/exclusão foram avaliados para o número, morfologia, local de origem, complexidade, IA e IP dos complexos ventriculares prematuros (CVPs) e da VFC no domínio do tempo. 0 efeito na sobrevida foi avaliado, considerado a presença/ausência de taquicardia ventricular (TV), e síncope. 0 desfecho final foi a mortalidade global, com o tempo de sobrevida mediano sendo obtido pela análise de Kaplan-Meier e comparado pelo teste de log-rank. CVPs polimórficos foram mais comuns em cães sintomáticos. Os CVPs em Boxers com TV foram menos prematuros, devido 
à influência da frequência cardíaca (FC) sobre o IP, apesar de IA comparáveis. O IP e a FC média diferiram entre os cães com TV e os sem, mas não discriminam adequadamente os grupos como variáveis isoladas. A sobrevida global foi menor nos cães com TV (463 dias vs 1645 dias, HR=4,31, $\mathrm{P}=0,03$ ). Os parâmetros da VFC, SDNN e SDANN, foram associados ao prognóstico. O IA e o IP não possuem valor prognóstico em Boxers com arritmias ventriculares. A FC média $\geq 112 \mathrm{bpm}$ é $100 \%$ sensível, mas apenas $46 \%$ específica para detectar Boxers com TV no Holter de 24 horas. A presença de TV, $\mathrm{SDNN} \leq 245 \mathrm{~ms}$, ou SDANN $\leq 134 \mathrm{~ms}$ no momento do primeiro Holter de 24 horas estão associados a menor sobrevida global no Boxer.

TERMOS DE INDEXAÇÃO: Prognóstico, intervalo de acoplamento, índice de prematuridade, frequência cardíaca, raça Boxer, arritmias, sistema nervoso simpático, morte súbita, cães.

\section{INTRODUCTION}

Arrhythmogenic right ventricular cardiomyopathy (ARVC) was first described in Boxer dogs in the early 1980's (Harpster 1983) as a myocardial disease in which cardiomyocytes are replaced by fibrofatty tissue, making affected dogs prone to developing ventricular arrhythmias (VA). Boxer ARVC is a familial disease apparently inherited as an autosomal dominant trait (Meurs et al. 1999). Three clinical presentations have been proposed: 1) asymptomatic dogs with occasional ventricular premature complexes (VPC), 2) Boxer dogs with tachyarrhythmias and syncope or exercise intolerance, and 3 ) least commonly diagnosed, animals with myocardial systolic dysfunction and ventricular dilation, sometimes with evidence of congestive heart failure - CHF (Harpster 1991a).

There is no single specific test to diagnose Boxer ARVC (Meurs 2017), and 24-hour Holter monitoring plays a fundamental role as part of screening, diagnosis, and monitoring of treatment in this condition. The severity of VA is usually described by the number, pattern, morphology and occurrence. Although many affected animals live a normal life, Boxer dogs with ARVC are at risk of sudden cardiac death (SCD), thus, the study of additional electrocardiographic characteristics may help stratify risk. The prognosis of Boxers with ARVC without CHF is widely variable and predicting outcome is usually challenging (Meurs 2017).

The coupling interval (CI) and the prematurity index (PI) of VA have been extensively studied in human beings, although the results are still controversial (Igarashi et al. 2012, Kim et al. 2014, Lee et al. 2014). In dogs with degenerative mitral valve disease, our group recently demonstrated that PI differs between symptomatic and pre-clinical stages, but the prognostic value of such indices has not been evaluated (Carvalho et al. 2018). However, heart rate variability (HRV), a non-invasive way to assess the interaction between the sympathetic and parasympathetic autonomic nervous system, is a well-established method to identify people at risk of developing CHF or SCD (Fauchier et al. 1997, 1999, Bikkina et al. 1998, Stein \& Kleiger 1999). Curiously, in Boxer dogs the prognostic value of HRV has not yet been completely characterized.

Therefore, the aims of this study were twofold: 1) to investigate the characteristics of VA, including the $\mathrm{CI}$ and PI, and the HRV variables in Boxer dogs with respect to clinical status and the presence/absence of ventricular tachycardia - previously established as an independent predictor of mortality in Boxer ARVC (Mõtskula et al. 2013); and 2) to evaluate the impact of such characteristics on the overall survival time.

\section{MATERIALS AND METHODS}

Study design and Ethics Statement. This was a retrospective study, approved by the institutional Animal Care and Use Committee (protocol 012277/17).

Animals. Boxer dogs investigated at the Cardiology section of a referral teaching practice were identified by searching the medical record database. The database was searched to identify all boxers which met the following inclusion criteria: $\geq 4$ years old, examined from 2012 to 2017, with an available conventional electrocardiography (ECG) (ECGPCVet, Tecnologia Eletrônica Brasileira, São Paulo, Brazil) a three-channel 24-hour Holter recording (CardioLight, Cardios Sistemas, São Paulo, Brazil) and echocardiography (My Lab 30, Esaote, Italy), performed by the attending cardiologist within seven days of one another. For animals in which more than one Holter recording was available, only the first examination was used for analysis. Dogs found to have any heart disease other than ARVC diagnosed by echocardiography, $\mathrm{CHF}$, a systemic disease process that could explain the observed arrhythmias (e.g., ehrlichiosis (Ferreira et al. 2017), neoplasia (Marino et al. 1994), as well as those with syncope due to neurocardiogenic bradycardia, and those receiving antiarrhythmics were excluded. Baseline clinical details obtained from medical records included age, gender, body weight, and history of syncope at the time of the first 24-hour Holter Recording.

Electrocardiographic evaluation. One investigator (E.R.C), who was blinded to the clinical status of dogs, manually reviewed Holter records checking the QRS templates, including possible misinterpretation for horizontal and vertical resolution, and checked the digital 24-hour editing program (CardioManenger S540, Cardios Sistemas, São Paulo, Brazil). Measurements, as well as analyses, were made on channel 1 of the Holter recording (positive pole toward the apex of the left ventricle).

Ventricular arrhythmias over a 24 hour period were characterized according to: 1) presence or absence of ventricular premature complexes (VPC); 2) number of VPCs; 3) site of origin of VPCs: right ventricle (left bundle branch block morphology - LBBB), left ventricle (right bundle branch block morphology - RBBB), or both; 4) VPC morphology: monomorphic (unifocal - same QRS morphology and polarity throughout the exam) or polymorphic (multifocal - QRS morphology changing with regard to amplitude and/or polarity); and 5) VPC complexity: isolated VPC, repeating patterns (e.g., couplets, triplets, bigeminy, trigeminy) or ventricular tachycardia (VT). VT was defined as a sequence of more than three consecutive large QRS complexes, with heart rate $(\mathrm{HR})>180$ beats $/ \mathrm{min}$ and atrioventricular dissociation. Holter recordings are not appropriate for accurate identification of true supraventricular arrhythmias, for this reason, detection of this arrhythmia was not included in analyses.

Boxers were further classified according to the degree of ventricular ectopy, based on the following criteria: 0 to 20 VPCs per 24 hours were interpreted as normal; 21 to 300 VPCs per 24 hours were interpreted as indeterminate; and animals with more than $300 \mathrm{VPCs} / 24 \mathrm{~h}$ were considered likely to be affected by ARVC (Meurs 2017).

In addition, the $\mathrm{CI}$ of VPC, defined as the R-R interval between the VPC and the preceding sinus complex, and the sinus cycle length (SCL), defined as the R-R interval of the sinus cycle just before the VPC, were determined as described elsewhere (Igarashi et al. 2012, Lee et al. 2014, Carvalho et al. 2018). The PI of VPCs was calculated 
as the ratio of CI to SCL. Five VPCs per dog were manually chosen at random, all measurements were made five times, the highest and lowest values were excluded and a mean of three measurements was used for statistical analysis. When the randomization included a run of VT, the first VPC of the run and the SCL from the sinus beats before the episode were used. Boxers with fewer than 5 VPCs recorded had all ventricular premature beats measured, and a mean was obtained.

The 24-h HRV was assessed at the time domain, and included the following parameters: 1) the standard deviation of the R-R intervals (SDNN); 2) the standard deviation of the mean $\mathrm{R}-\mathrm{R}$ intervals obtained at 5 minute intervals (SDANN); 3 ) the mean of the standard deviation of the R-R intervals obtained at 5 minute intervals (SDNNidx); 4) the square root of the mean squared differences of successive R-R intervals (rMSSD); 5) percentage of adjacent $\mathrm{R}-\mathrm{R}$ intervals differing in duration by more than 50 milliseconds ( $\mathrm{pNN}>50$ ); 6) minimum HR over 24-hour recording (HRmin); 7) mean HR (HRme); and 8) maximum HR (HRmax).

Survival analyses. Was performed using an end-point of all-causes of death. Follow-up information was documented from medical records or a telephone call with owners, in up to six attempts over a number of days. If survival data were still incomplete, referring veterinarians were contacted. Outcome data included patient status (alive or dead), date of death or euthanasia, and the probable cause of death. Additionally, owners were asked whether there was a family history of ARVC. SCD was defined as an unexpected death without apparent clinical signs during the preceding 24 hours (Meurs et al. 2011). For dogs that were still alive at the end of the study, or those lost to follow-up, the date that were last seen alive was recorded and then they were censored of the analysis.

Statistical analyses. The Shapiro-Wilk test was used to investigate the normal distribution of data. Syncopal and non-syncopal animals and dogs that presented with VT and those without were compared using either Mann-Whitney test or Student's t-test according to distribution. Parametric data are represented as mean \pm standard deviation, while non-parametric variables are shown as median (interquartile range). The contingency was evaluated using either Fisher's exact test or the Chi-square when three or more categories were compared. Receiver operating characteristic (ROC) curves were constructed to investigate sensitivity and specificity of CI, PI and HRV parameters to distinguish dogs with VT from those without, as VT has previously been established as an independent predictor of mortality in Boxer ARVC (Mõtskula et al. 2013). Kaplan-Meier survival curves were constructed and compared using the log-rank test to identify factors that significantly influenced mortality, and to estimate median survival time. Statistical processing was performed using commercially available statistical software (Prism Windows 6.0, GraphPad Software, California, USA), and significance was defined as $\mathrm{P}<0.05$.

\section{RESULTS}

A total of 36 dogs met the inclusion/exclusion requirements and were included in this study. The sample comprised 17 females and 19 males, with a mean of 8 (6-10.8 y) years old, weighing $27.9 \mathrm{~kg}$ (24.3-32kg). Fourteen animals (38.9\%) had $\leq$ than 20 VPCs /24-h and were considered normal, seven (19.4\%) had between 21 and 300 VPCs/24-h being considered as indeterminate to ARVC, and fifteen (41.7\%) had more than 300 VPCs/24-h and were considered likely to be affected by ARVC. Ten dogs (27.8\%) had only VPCs with first deflection positive, suggesting the right ventricle as site of origin, five (13.9\%) animals had only VPCs with the first deflection negative, suggesting the left ventricle as site of origin, and twenty-one (58.3\%) dogs showed both.

Seven dogs (18.9\%) experienced syncope at the time of first 24-h Holter recording, and no animal had clinical signs of CHF (ascites, pulmonary edema, and pleural effusion). Characteristics evaluated in syncopal and non-syncopal Boxer dogs are summarized in Table 1. Age and weight did not differ between groups; however, male dogs were overrepresented in the syncopal group $(\mathrm{P}=0.001)$. In addition, symptomatic patients were found to have more polymorphic VPCs ( $\mathrm{P}=0.0002)$, as well as a higher SDNN ( $\mathrm{P}=0.02)$ and SDNNidx $(\mathrm{P}=0.009)$.

After the first 24-h Holter recording, Boxer dogs that had syncope, and/or VPCs in couplets, triplets, bigeminy or VT, regardless of the number of VPCs, were given antiarrhythmic therapy, a total of 18 animals (48.6\%). The most commonly prescribed drug was sotalol (77.8\%) at a dose of $30-60 \mathrm{mg}$ per dog orally every 12 hours. Amiodarone was prescribed to four animals (22.2\%), at a dose of 150-200mg per dog orally every 12 hours. Twelve dogs (66.7\%) received omega-3 fish oil (500mg orally daily) in addition to sotalol or amiodarone.

Boxers were categorized according to the presence of VT, and the CI, SCL, PI, and HRV features were compared, as shown in Table 2. The CI was considered similar between dogs with or without VT ( $\mathrm{P}=0.09)$, however, the SCL was shorter in the VT group (280 vs 410ms; $\mathrm{P}=0.008$ ), therefore, the PI was higher (less premature) in these patients $(0.85$ vs $0.68, \mathrm{P}=0.02)$. Furthermore, among HRV parameters, only the HRme differed between non-VT and VT dogs, being higher in the latter ( 89 vs $104 \mathrm{bpm}, \mathrm{P}=0.01$ ).

Areas under the curve (AUC) above 0.5 were obtained for CI, PI and HRV parameters to try to differentiate dogs with VT from others at the time of the first 24-h Holter (Table 3), but only PI (AUC=0.73, $\mathrm{P}=0.02$ ) and HRme (AUC=0.72, $\mathrm{P}=0.03$ ) were considered relevant. For this reason, two proposed cut-off values to PI and HRme, based on the better match between specificity and sensitivity, are presented in Table 4.

Median follow-up period for the whole population was 700 days (354-934 days). Sixteen dogs (44.4\%) reached the end-point. Among them, three animals were euthanized due to end-stage cancer (18.75\%), SCD occurred in two $(12.5 \%)$, and eleven died of unknown causes (68.75\%). Among dogs that died suddenly, one had 8 isolated monomorphic VPCs over 24-h, and another 2 isolated monomorphic VPCs and a run of VT of 8 seconds over 24-h at the time of first Holter.

A family history of ARVC was known in five animals (13.9\%, 7-11 years old), with three dogs having ARVC parents that died suddenly, and two with healthy parents. The three dogs with family history of ARVC showed more than 300 polymorphic VPCs/24-h. Also, two of these dogs had VT and syncope, and the third had isolated VPCs and was asymptomatic at the time of the first Holter monitoring.

Median survival time was significantly shorter for dogs with VT compared to those with isolated or repeated patterns of VPC (463 vs 1173 days, HR=4.25, 95\% CI=1.23-14.64, $\mathrm{P}=0.02)$. The presence of couplets, triplets and bigeminy were not statistically significant $(\mathrm{P}=0.057)$. There was no significant difference in survival time between the dogs in the monomorphic or polymorphic VPCs group $(\mathrm{P}=0.26)$. The presence of syncope $(\mathrm{P}=0.78)$, number of VPCs over 24-h $(\mathrm{P}=0.18)$, as well as $\mathrm{CI}(\mathrm{P}=0.29)$ and $\mathrm{PI}(\mathrm{P}=0.62)$ was 
Table 1. Sample characterization, characteristics of ventricular arrhythmias and time domain heart rate variability in 36 adult Boxer dogs according to the presence of syncope

\begin{tabular}{|c|c|c|c|}
\hline & Non-syncopal $(\mathrm{n}=30)$ & Syncopal $(\mathrm{n}=6)$ & $\mathrm{P}$ \\
\hline Age (years) & $8.1 \pm 2.8^{\mathrm{a}}$ & $7.7 \pm 2.8$ & 0.77 \\
\hline Body weight (kg) & $26.5(24-30.4)^{\mathrm{b}}$ & $32.8(22.4-40)$ & 0.42 \\
\hline \multicolumn{4}{|l|}{ Gender (\%) } \\
\hline Male & 47 & 72 & \\
\hline Number of VPC & $25(3-2538)$ & $1023(47-3517)$ & 0.22 \\
\hline Polymorphic & 62 & 86 & \\
\hline Occurrence & & & 0.11 \\
\hline Isolated & 45 & 42 & \\
\hline Repeated patterns & 17 & 29 & \\
\hline VT & 38 & 29 & \\
\hline HRmax (bpm) & $235(226-250)$ & $250(223-250)$ & 0.38 \\
\hline SDNN (ms) & $300(245-352)$ & 369 (327-429) & 0.02 \\
\hline SDANN (ms) & $170 \pm 55$ & $210 \pm 43$ & 0.09 \\
\hline SDNNidx & $236(178-282)$ & 297 (269-353) & 0.009 \\
\hline rMSSD (ms) & $135.5 \pm 62.4$ & $151.4 \pm 70$ & 0.56 \\
\hline pNN>50 (\%) & $45.8 \pm 14.7$ & $57.5 \pm 8.9$ & 0.05 \\
\hline
\end{tabular}

$\overline{\mathrm{a}, \mathrm{b}}$ Parametric data are represented as mean \pm standard deviation, while non-parametric variables are shown as median (interquartile range); Repeated patterns: couplets, triplets, bigeminy, trigeminy; VT = ventricular tachycardia, HRmin = minimum heart rate over 24 hours, HRme = mean heart rate over 24h, HRmax = maximum heart rate over $24 \mathrm{~h}, \mathrm{SDNN}=$ the standard deviation of the RR intervals, SDANN = the standard deviation of the mean RR intervals obtained at 5 minute intervals, SDNNidx = mean of the standard deviation of the RR intervals obtained at 5 minute intervals, rMSSD $=$ the square root of the mean squared differences of successive RR intervals, $\mathrm{pNN}>50=$ percentage of adjacent RR intervals differing by more than 50 milliseconds in duration.

Table 2. Electrocardiographic features of ventricular arrhythmias and time domain heart rate variability in 36 adult Boxer dogs according to the presence of ventricular tachycardia

\begin{tabular}{|c|c|c|c|c|c|c|c|c|c|c|c|}
\hline & CI (ms) & SCL (ms) & PI & $\begin{array}{c}\text { HRmin } \\
\text { (bpm) }\end{array}$ & $\begin{array}{l}\text { HRme } \\
\text { (bpm) }\end{array}$ & HRmax (bpm) & SDNN (ms) & $\begin{array}{c}\text { SDANN } \\
(\mathrm{ms})\end{array}$ & SDNNidx & $\begin{array}{c}\text { rMSSD } \\
(\mathrm{ms})\end{array}$ & $\begin{array}{c}\mathrm{pNN}>50 \\
(\%)\end{array}$ \\
\hline VT (n=13) & $280(260-340)^{a}$ & $360(280-475)$ & $0.85 \pm 0.12^{b}$ & $43 \pm 12$ & $104 \pm 21$ & 231 (229-248) & $292(140-386)$ & $158 \pm 68$ & $223(103-333)$ & $114 \pm 69$ & $45 \pm 17$ \\
\hline Non-VT ( $\mathrm{n}=23)$ & $320(300-380)$ & $490(410-600)$ & $0.68 \pm 0.20$ & $38 \pm 6$ & $89 \pm 10$ & $245(224-250)$ & 317 (278-374) & $186 \pm 42$ & $252(201-300)$ & $150 \pm 56$ & $50 \pm 13$ \\
\hline $\mathrm{P}$ & 0.09 & 0.008 & 0.02 & 0.11 & 0.01 & 0.29 & 0.37 & 0.14 & 0.38 & 0.09 & 0.34 \\
\hline
\end{tabular}

a,b Parametric data are represented as mean \pm standard deviation, while non-parametric variables are shown as median (interquartile range); $\mathrm{VT}=$ ventricular tachycardia, $\mathrm{CI}=$ coupling interval, $\mathrm{SCL}=$ sinus cycle length, $\mathrm{PI}=$ prematurity index, $\mathrm{HRmin}=$ minimum heart rate over 24 hours, $\mathrm{HRme}=$ mean heart rate over $24 \mathrm{~h}, \mathrm{HRmax}=$ maximum heart rate over $24 \mathrm{~h}, \mathrm{SDNN}=$ the standard deviation of the RR intervals, SDANN $=$ the standard deviation of the mean RR intervals obtained at 5 minute intervals, SDNNidx = mean of the standard deviation of the RR intervals obtained at 5 minute intervals, Rmssd = the square root of the mean squared differences of successive RR intervals, $\mathrm{pNN}>50=$ percentage of adjacent RR intervals differing by more than 50 milliseconds in duration.

Table 3. Receiver operating characteristic of coupling interval, prematurity index and time domain heart rate variability parameters to distinguish adult Boxer dogs with ventricular tachycardia from those without VT

\begin{tabular}{|c|c|c|c|c|c|c|c|c|c|c|}
\hline & $\mathrm{CI}$ & $\mathrm{PI}$ & HRmin & HRme & HRmax & SDNN & SDANN & SDNNidx & rMSSD & $\mathrm{pNN}>50$ \\
\hline AUC & 0.67 & 0.73 & 0.60 & 0.72 & 0.60 & 0.59 & 0.62 & 0.59 & 0.68 & 0.58 \\
\hline $95 \%$ CI & $0.46-0.87$ & $0.56-0.89$ & $0.39-0.81$ & $0.53-0.90$ & $0.41-0.80$ & $0.38-0.80$ & $0.40-0.83$ & $0.37-0.80$ & $0.48-0.87$ & $0.36-0.78$ \\
\hline $\mathrm{P}$ & 0.09 & 0.02 & 0.31 & 0.03 & 0.30 & 0.36 & 0.23 & 0.37 & 0.08 & 0.45 \\
\hline
\end{tabular}

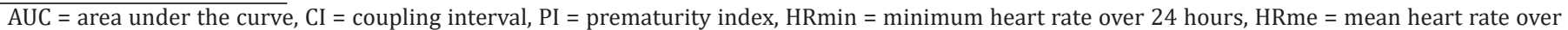

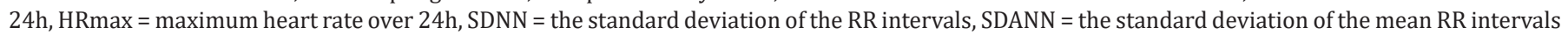

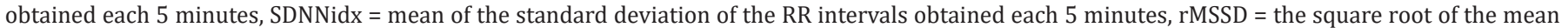
squared differences of successive RR intervals, pNN>50= percentage of adjacent RR intervals differing by more than 50 milliseconds in duration. 

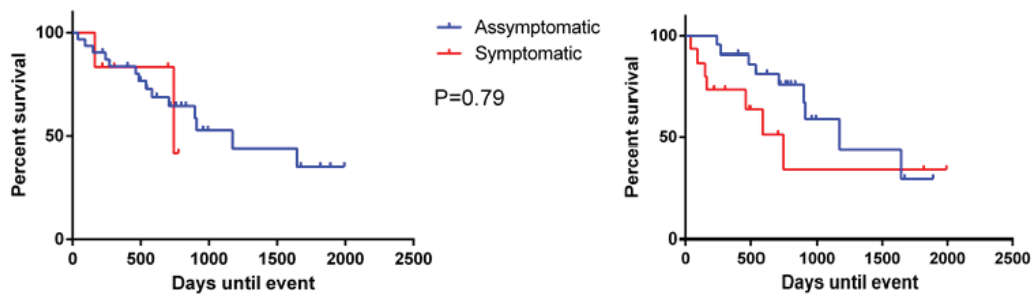

$-\leq 300 \mathrm{VPCs} / 24 \mathrm{~h}$
$+>300 \mathrm{VPCs} / 24 \mathrm{~h}$

$\mathrm{P}=0.18$
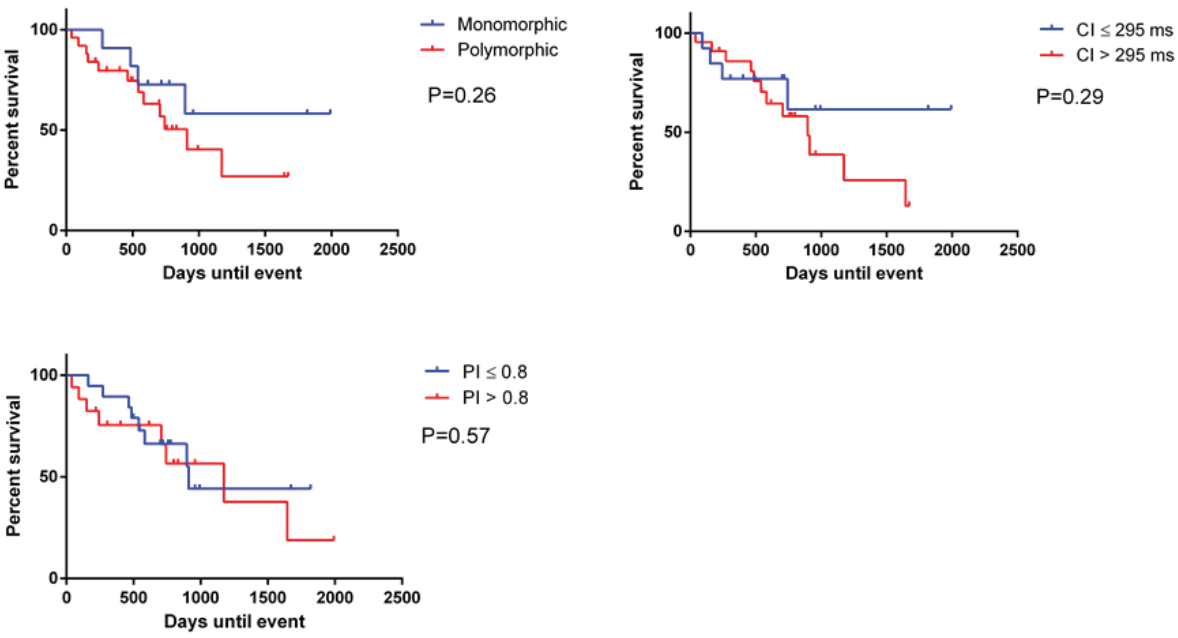

Fig.1. Kaplan-Meier analyses used to assess the prognostic value of several characteristics of ventricular arrhythmias and syncope in 36 adult Boxer dogs. The end-point was all-cause of death. VPCs = ventricular premature complexes, $\mathrm{CI}=$ coupling interval, $\mathrm{PI}=$ prematurity index

Table 4. Cut-off values to prematurity index (PI) and mean heart rate (HRme) that better distinguished Boxer dogs with ventricular tachycardia (VT) from others at the time of the first $24 \mathrm{~h}$ Holter recording

\begin{tabular}{lcccc}
\hline & Cut-off & $\begin{array}{c}\text { Sensitivity } \\
(\%)\end{array}$ & $\begin{array}{c}\text { Specificity } \\
(\%)\end{array}$ & $\begin{array}{c}\text { Likelihood } \\
\text { ratio }\end{array}$ \\
\hline PI & 0.79 & 65.22 & 69.23 & 2.12 \\
& 0.83 & 65.22 & 53.85 & 1.41 \\
HRme & 94 & 76.16 & 53.85 & 1.65 \\
(bpm) & 112 & 100 & 46.15 & 1.85
\end{tabular}

not associated with overall survival at the proposed cut-off values, as shown in Figure 1.

Of the HRV features, SDNN was shown to be associated with prognosis $(\mathrm{SDNN}>245 \mathrm{~ms}=1645$ days $v s \mathrm{SDNN} \leq 245 \mathrm{~ms}=271$ days, $\mathrm{HR}=19.97,95 \%$ of $\mathrm{CI}=3.91-101.8, \mathrm{P}=0.0003$ ), also SDANN $($ SDANN $>134 \mathrm{~ms}=1645$ days $v s$ SDANN $\leq 134 \mathrm{~ms}=463$ days, $\mathrm{HR}=3.95,95 \% \mathrm{CI}=2.13-38.79$, $\mathrm{P}=0.01$ ) (Fig.2). Survival analyses according to HRV features are summarized in Table 5.

\section{DISCUSSION}

In this study, the impact on overall survival of some characteristics of ventricular arrhythmias and heart rate variability on the first 24-h Holter monitoring in thirty-six Boxer dogs was assessed. In these analyses, both the dogs with syncope and those examined for routine breed screening were included. The mean age in the whole population was similar, approximately 8 years old, although only animals' $\geq 4$ years old were actually accepted into the study. Boxer ARVC is usually of adult-onset, more frequently seen in animals above 5 years
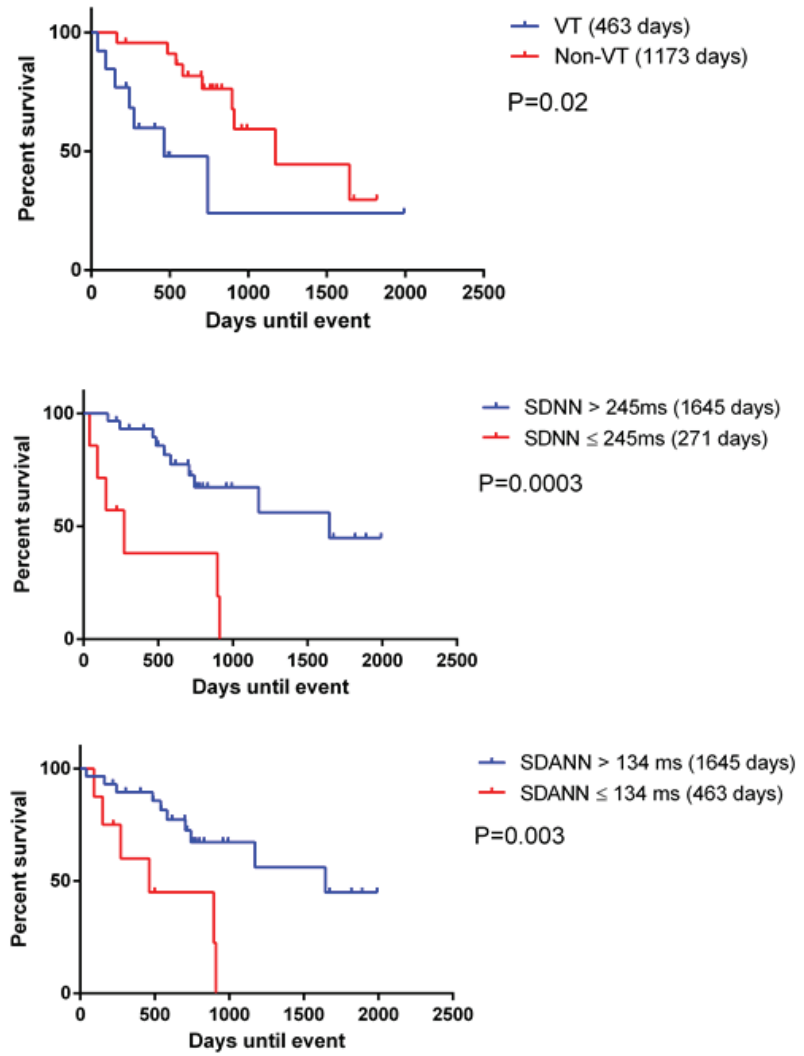

Fig.2. Kaplan-Meier analyses with prognostic value at the first 24-Hour Holter monitoring in 36 adult Boxer dogs. The end-point was all-cause of death. VT = ventricular tachycardia, $\mathrm{SDNN}=$ the standard deviation of the RR intervals, SDANN = the standard deviation of the mean RR intervals obtained at 5 minutes intervals, over 24-hours. 


\section{Table 5. Log-rank comparison of Kaplan-Meier survival curves analyses of heart rate variability features to the proposed cut-off values (in parentheses), in 36 Boxer dogs monitored by $24 \mathrm{~h}$ Holter}

\begin{tabular}{ll}
\hline \multicolumn{1}{c}{ Parameter } & \multicolumn{1}{c}{$\mathrm{P}$} \\
\hline SDNN (245 ms) & 0.0003 \\
SDANN (134 ms) & 0.003 \\
SDNNidx (192 ms) & 0.16 \\
rMSSD (173 ms) & 0.14 \\
pNN>50\% & 0.26 \\
HRmin (37 bpm) & 0.34 \\
HRme (95 bpm) & 0.07 \\
HRmax (247 bpm) & 0.16
\end{tabular}

SDNN = the standard deviation of the RR intervals, SDANN = the standard deviation of the mean RR intervals obtained at 5 minutes intervals, over 24 hours, SDNNidx = mean of the standard deviation of the RR intervals obtained each 5 minutes, rMSSD = the square root of the mean squared differences of successive RR intervals, $\mathrm{pNN}>50 \%=$ percentage of adjacent RR intervals differing by more than 50 milliseconds in duration, $\mathrm{HRmin}=$ minimum heart rate over 24 hours, $\mathrm{HRme}=$ mean heart rate over $24 \mathrm{~h}, \mathrm{HRmax}=$ maximum heart rate over $24 \mathrm{~h}$.

of age. Among symptomatic dogs, a male predominance was observed, similarly to previously reported data (Harpster 1991b, Palermo et al. 2011).

The diagnosis of ARVC is best based on a combination of findings, that may include a middle age Boxer dog with syncope, ventricular arrhythmias with left bundle branch block morphology in caudoventral leads (II, III and aVF) (Kraus et al. 2002) without other documentable causes for the arrhythmia, and a family history of disease (Meurs et al. 1999, Meurs 2017). Although in man the familial history of ARVC is considered a major criterion for diagnosis (McKenna et al. 1994), in this study the family history was known in only three dogs, $13.9 \%$ of cases.

The number of VPCs over 24-h was not statistically different between asymptomatic and symptomatic dogs. In addition, the complexity of VA did not differ between symptomatic and asymptomatic dogs. The small number of symptomatic dogs enrolled in our study may have affected these findings. Palermo et al. (2011) found that symptomatic Boxers with ventricular dilation (form 3 of ARVC) usually had a higher number of ventricular ectopic beats, in addition to more complex arrhythmias (couplets, triplets, VT) in comparison to those without ventricular dilation (forms 1 and 2). However, only a small proportion of dogs in Palermo's study had a Holter recording available, making it difficult to draw conclusions regarding the association between the different ARVC forms and either severity or frequency of arrhythmias.

Although 24-h Holter monitoring provides a better assessment of presence, overall frequency and complexity of VA and should be used as part of the diagnosis of Boxer ARVC (Meurs 2004, Palermo et al. 2011), there is no established cut-off for the number of VPCs over 24-hour that would classify a Boxer as ARVC affected. Ventricular arrhythmias have a spontaneous daily variability, which can be as high as $80 \%$ in Boxer dogs with ARVC (Spier \& Meurs 2004a). The proposed cut-off value of 300 VPCs over 24-h was not associated with a worse prognosis in this study, contrasting with another investigation in which more than 50 VPCs/24-h was associated with a shorter survival (Mõtskula et al. 2013).

Symptomatic Boxer dogs are more likely to have polymorphic VPCs, in concordance with what has been previously reported in Boxer dogs with CHF due to ARVC (Mõtskula et al. 2013), and symptomatic dogs with degenerative mitral valve disease (Carvalho et al. 2018). Although survival was considered similar between Boxer dogs exhibiting either monomorphic or polymorphic VA $(\mathrm{P}=0.057)$, the difference in median survival between these groups has clinical significance (1993 vs 910 days). Other authors have previously reported that polymorphism is associated with cardiac mortality in Boxer dogs (Mõtskula et al. 2013). The impact of polymorphic ventricular arrhythmias on mortality has not been clearly elucidated in veterinary studies. In the human medical literature, however, it is recognized as a negative prognostic indicator, especially polymorphic VT, which is considered a rhythm with a potential to progress to ventricular fibrillation, a major cause of sudden cardiac death (Haissaguerre et al. 2016). None of animals on this study had polymorphic VT.

The presence of VT was associated with an increased all-cause mortality in this study, similar to previously studies, in which Boxer dogs with VT were about 3 times more likely to suffer cardiac death (Mõtskula et al. 2013, Chamas et al. 2016). In people, many studies have reported that more frequent VPCs are closely associated with ventricular dilation, systolic dysfunction, malignant forms of VT, as well as a poor prognosis (Duffee et al. 1998, Shiraishi et al. 2002, Takemoto et al. 2005, Rhee et al. 2006, Sheldon et al. 2010, Del Carpio Munoz et al. 2011, Igarashi et al. 2012, Kim et al. 2014). Although the PI and HRme were the two evaluated variables that better distinguished dogs with VT from the remaining population, the specificity and sensitivity obtained for PI were low, and none of them were associated with prognosis. However, the HRme $=112 \mathrm{bpm}$ was $100 \%$ sensitive but only $46 \%$ specific for VT, meaning that all dogs without VT had an HRme <112 bpm. This finding suggests that if VT is not observed in a 24-hour Holter record in an adult Boxer but HRme is above $112 \mathrm{bpm}$, it could be reasonable to pursue further Holter monitoring.

Boxer dogs with ARVC can experience SCD regardless of presence/absence of clinical signs (Meurs 2017). Our findings suggested that syncope at the time of the first 24-h Holter monitoring was not associated with a worse prognosis, however our population was heterogenous and only $41.7 \%$ was considered likely to be affected by ARVC according to the degree of ventricular ectopy. Palermo et al. 2011 found that the presence of syncope was associated with shorter survival times in Boxers affected with ARVC. Drawing conclusions about the significance of syncope and survival in Boxer dogs is difficult, as the majority of symptomatic animals received antiarrhythmic therapy after the first Holter, which may skew the survival analyses.

There has been interest in the study of VPC CI and PI as an aid to better stratification of risk in patients with VA, although these variables have been poorly investigated in veterinary patients. In human patients, results are conflicting, likely reflecting heterogeneous study populations (Haissaguerre et al. 2002, Viskin et al. 2005, Knecht et al. 2011, Igarashi et al. 2012). The CI and PI were not statistically significant different between symptomatic and asymptomatic Boxer dogs, in contrast with our own study in dogs with mitral 
endocardiosis, in which the VPCs in symptomatic animals were less premature (Carvalho et al. 2018). However, the VPCs of dogs with clinical mitral endocardiosis could be considered relatively less premature, mainly because the influence of heart rate, or sinus cycle length, at PI. In addition, these two variables were not associated with overall mortality, and, at least to the best of our knowledge, this was the first time that the prognostic value of CI and PI has been evaluated in Boxer dogs. The VPCs in dogs with VT were found to be less premature (higher PI), due to a shorter sinus cycle length, despite CI being comparable to those without VT. The authors believe these findings could be explained by the effect of heart rate on the prematurity index, since dogs with VT had higher mean heart rate and thus higher PI. Moreover, PI at the proposed cut-off values does not adequately distinguish patients with and without VT.

The HRV is determined by autonomic nervous system activity. The propensity for lethal arrhythmias associated with either increased sympathetic or reduced vagal activity, reflected as decreased HRV, have been extensively studied in people (Bikkina et al. 1998, Obias-Manno \& Wijetunga 2004, Frigy et al. 2018). From our data, some HRV variables, such as SDNN and SDNNidx, in symptomatic Boxer dogs were higher than in the asymptomatic group. When looking at animals with VT, only HRme was different from the other parameters, suggesting that elevated HRme ( $\geq 112 \mathrm{bpm})$ could be associated with an increased risk of developing VT, although with a poor specificity. Previous studies of HRV in Boxer dogs did not identify a lower HRV in patients with complex and frequent VA (Spier \& Meurs 2004b, Zacché et al. 2017). Although HRV was not evaluated in relation to syncope in such investigations, Boxer dogs with CHF had a lower HRV (Spier \& Meurs 2004a, Haissaguerre et al. 2016, Chamas et al. 2016). Our findings suggest that symptomatic Boxer dogs, as well as those with VT and no CHF, did not have a persistently high sympathetic tone, or HRV changes have reflected subclinical diseases processes at the time that the first 24-hour Holter was made.

Nevertheless, the SDNN and SDANN, estimates of long-term components of HRV, which are thought to be more sympathetically mediated of HRV (Malliani et al. 1991, Montano et al. 1994), were found to have prognostic value in Boxer dogs, as a SDNN $\leq 245 \mathrm{~ms}$, or SDANN $\leq 134 \mathrm{~ms}$ were associated with worse outcome. Conversely, a reduced HRV has already been associated with CHF and risk of SCD in people with VA (Fauchier et al. 1999, Stein \& Kleiger 1999). Chamas et al. (2016) found no association between HRV variables and outcome in Boxer dogs, even though the lowest SDANN (58 $\pm 13 \mathrm{~ms}$ ) was documented in animals with CHF, as previously reported by Spier \& Meurs (2004a) (82 $\pm 21 \mathrm{~ms}$ ).

The results of this study should be interpreted in the context of its limitations. This was a retrospective investigation and accepts the inherent criticisms of the methodology. The unequal groups and small sample size with regard to syncope, limits the stratification of VA characteristics and HRV between such individuals. The total sample size was small, including Boxer dogs considered normal, equivocal and likely affected by ARVC. In addition, at the end of follow-up period fewer than $50 \%$ of population had reached the end-point. Although any cause of mortality is of clinical relevance, a study to asses cardiac mortality would be preferable. Finally, the influence of antiarrhythmic therapy after the first 24-h Holter potentially played a major role in overall survival, and this was not standardized due to the retrospective methodology. Despite all the limitations, these preliminary results add new information about the risk stratification in Boxer dogs with VA, and may contribute to prospective studies.

\section{CONCLUSIONS}

Symptomatic Boxer dogs are more likely to have polymorphic VPCs than asymptomatic ones.

The VPCs of dogs with ventricular tachycardia are relatively less premature, probably due to the heart rate influence over the prematurity index in spite of a comparable coupling interval.

The PI and HRme were significant different between VT and non-VT dogs, whilst these parameters alone did not discriminate adequately between groups, HRme may provide additional information regarding the presence of VT, in a population known to have significant day-to-day variation of VA.

The presence of VT, SDNN $\leq 245 \mathrm{~ms}$, or SDANN $\leq 134 \mathrm{~ms}$ in an adult Boxer dog at the time of the first 24-h Holter recording is associated with a shorter overall survival time.

Conflict of interest statement.- The authors have no competing interests.

\section{REFERENCES}

Bikkina M., Alpert M.A., Mukerji R., Mulekar M., Cheng B.Y. \& Mukerji V. 1998. Diminished short-term heart rate variability predicts inducible ventricular tachycardia. Chest113(2):312-316. <http://dx.doi.org/10.1378/chest.113.2.312> <PMid:9498944>

Carvalho E.R., Ampuero R.A.N., Tuleski G.L.R., Camacho A.A. \& Sousa M.G. 2018. Polymorphism, coupling interval and prematurity index in dogs with degenerative mitral valve disease and ventricular arrhythmias. Vet. Res. Commun. 42(2):18. <http://dx.doi.org/10.1007/s11259-018-9718-0> <PMid:29536334>

Chamas P.P.C., Oliveira V.M.C., Yamaki F.L., Goldfeder G.T. \& Larsson M.H.M.A. 2016. Valor prognóstico da variabilidade da frequência cardíaca e da eletrocardiografia ambulatorial em cães Boxer com cardiomiopatia arritmogênica do ventrículo direito. Arq. Bras. Med. Vet. Zootec. 68(5):1219-1227. <http://dx.doi. org/10.1590/1678-4162-8383>

Del Carpio Munoz F., Syed F.F., Noheria A., Cha Y.M., Friedman P.A., Hammill S.C., Munger T.M., Venkatachalam K.L., Shen W.K., Packer D.L. \&Asirvatham S.J. 2011. Characteristics of premature ventricular complexes as correlates of reduced left ventricular systolic function: study of the burden, duration, coupling interval, morphology and site of origin of PVCs. J. Cardiovasc. Electrophysiol. 22(7):791-798. <http://dx.doi.org/10.1111/j.1540-8167.2011.02021.x> $<$ PMid:21332870>

Duffee D.F., Shen W.K. \& Smith H.C. 1998. Suppression of frequent premature ventricular contractions and improvement of left ventricular function in patients with presumed idiopathic dilated cardiomyopathy. Mayo Clin. Proc. 73(5):430-433. <http://dx.doi.org/10.1016/S0025-6196(11)63724-5> <PMid:9581582>

Fauchier L., Babuty D., Cosnay P., Autret M.L. \& Fauchier J.P. 1997. Heart rate variability in idiopathic dilated cardiomyopathy: characteristics and prognostic value. J. Am. Coll. Cardiol. 30(4):1009-1014. <http://dx.doi.org/10.1016/ S0735-1097(97)00265-9><PMid:9316532>

Fauchier L., Babuty D., Cosnay P. \& Fauchier J.P. 1999. Prognostic value of heart rate variability for sudden death and major arrhythmic events in patients with idiopathic dilated cardiomyopathy. J. Am. Coll. Cardiol. 33(5):1203-1207. <http://dx.doi.org/10.1016/S0735-1097(99)00021-2><PMid:10193717>

Ferreira G.B., Filippi M.G. \& Paes A.C. 2017. Electrocardiographic evaluation in dogs with monocytic ehrlichiosis. Revta Educ. Contin. Med. Vet. Zootec. CRMV-SP 15:38-44.

Frigy A., Csiki E., Carașca C., Szabó I.A. \& Moga V.D. 2018. Autonomic influences related to frequent ventricular premature beats in patients without structural 
heart disease. Medicine, Baltimore 97(28):1-10.<http://dx.doi.org/10.1097/ MD.0000000000011489><PMid:29995813>

Haissaguerre M., Shoda M., Jais P., Nogami A., Shah D.C., Kautzner J., Arentz T., Kalushe D., Lamaison D., Griffith M., Cruz F., de Paola A., Gaïta F., Hocini M., Garrigue S., Macle L., Weerasooriya R. \& Clémenty J. 2002. Mapping and ablation of idiopathic ventricular fibrillation. Circulation 106(8):962-967. <http:// dx.doi.org/10.1161/01.CIR.0000027564.55739.B1><PMid:12186801>

Haissaguerre M., Vigmond E., Stuyvers B., Hocini M. \& Bernus 0. 2016. Ventricular arrhythmias and the His-Purkinje system. Nat. Rev. Cardiol. 13(3):155-166. <http://dx.doi.org/10.1038/nrcardio.2015.193> <PMid:26727298>

Harpster N.K. 1983. Boxer cardiomyopathy, p.329-337. In: Kirk R. (Ed), Current Veterinary Therapy VIII. W.B Saunders, Philadelphia, USA.

Harpster N.K. 1991a. Boxer cardiomyopathy. Vet. Clin. N. Am., Small Anim. Pract. 21(5):989-1004. <http://dx.doi.org/10.1016/S0195-5616(91)50107-8>

Harpster N.K. 1991b. Boxer cardiomyopathy: a review of the long-term benefits of antiarrhythmic therapy. Vet. Clin. N. Am., Small Anim. Pract. 21(5):989-1004. <http://dx.doi.org/10.1016/S0195-5616(91)50107-8><PMid:1949503>

Igarashi M., Tada H., Kurosaki K., Yamasaki H., Akiyama D., Sekiguchi Y., Kuroki K., Machino T., Murakoshi N., Nakata Y., Kuga K., Nogami A. \& Aonuma K. 2012. Electrocardiographic determinants of the polymorphic QRS morphology in idiopathic right ventricular outflow tract tachycardia.J. Cardiovasc. Electrophysiol. 23(5):521-526. <http://dx.doi.org/10.1111/j.1540-8167.2011.02232.x> $<$ PMid:22136173>

Kim Y.R., Nam G.B., Kwon C.H., Lee W.S., Kim Y.G., Hwang K.W., Kim J., Choi K.J. \& Kim Y.H. 2014. Second coupling interval of nonsustained ventricular tachycardia to distinguish malignant from benign outflow tract ventricular tachycardias. Hear Rhythm 11(12):2222-2230.<http://dx.doi.org/10.1016/j. hrthm.2014.08.012><PMid:25111325>

Knecht S., Sacher F., Wright M., Hocini M., Nogami A., Arentz T., Petit B., Franck R., De Chillou C., Lamaison D., Farré J., Lavergne T., Verbeet T., Nault I., Matsuo S., Leroux L., Weerasooriya R., Cauchemez B., Lellouche N., Derval N., Narayan S.M., Jaïs P., Clementy J. \& Haïssaguerre M. 2011. Long-term follow-up of idiopathic ventricular fibrillation ablation a multicenter study. J. Am. Coll. Cardiol. 54(6):522-528. <http://dx.doi.org/10.1016/j.jacc.2009.03.065> <PMid:19643313>

Kraus M.S., Moïse N.S., Rishniw M., Dykes N. \& Erb H.N. 2002. Morphology of ventricular arrhythmias in the boxer as measured by 12-lead electrocardiography with pace-mapping comparison. J. Vet. Intern. Med. 16(2):153-158. <http:// dx.doi.org/10.1111/j.1939-1676.2002.tb02347.x><PMid:11899030>

Lee Y.H., Zhong L., Roger V.L., Asirvatham S.J., Shen W.K., Slusser J.P., Hodge D.O. $\&$ Cha Y.M. 2014. Frequency, origin, and outcome of ventricular premature complexes in patients with or without heart diseases. Am. J. Cardiol. 114(9):13731378. <http://dx.doi.org/10.1016/j.amjcard.2014.07.072><PMid:25205629>

Malliani A., Pagani M., Lombardi F. \& Cerutti S. 1991. Cardiovascular neural regulation explored in the frequency domain. Circulation 84(2):482-492. <http://dx.doi.org/10.1161/01.CIR.84.2.482> <PMid:1860193>

Marino D.J., Matthiesen D.T., Fox P.R., Lesser M.B. \& Stamoulis M.E. 1994. Ventricular arrhythmias in dogs undergoing splenectomy: a prospective study. Vet. Surg. 23(2):101-106. <http://dx.doi.org/10.1111/j.1532-950X.1994.tb00453.x> <PMid:8191668>

McKenna W.J., Thiene G., Nava A., Fontaliran F., Blomstrom-Lundqvist C., Fontaine G., Camerini F., \& Task Force of the Working Group Myocardial and Pericardial Disease of the European Society of Cardiology and of the Scientific Council on Cardiomyopathies of the International Society and Federation of Cardiology. 1994. Diagnosis of arrhythmogenic right ventricular dysplasia/ cardiomyopathy. Brit. Heart J. 71(3):215-218. <http://dx.doi.org/10.1136/ hrt.71.3.215><PMid:8142187>

Meurs K.M. 2004. Boxer dog cardiomyopathy: an update. Vet. Clin. N. Am., Small Anim.Pract.34(5):1235-1244.<http://dx.doi.org/10.1016/j.cvsm.2004.05.003> <PMid:15325480>

Meurs K.M. 2017. Arrhythmogenic right ventricular cardiomyopathy in the boxer dog: an update. Vet. Clin. N. Am., Small Anim. Pract. 47(5):1103-1111. <http:// dx.doi.org/10.1016/j.cvsm.2017.04.007><PMid:28647112>
Meurs K., Lahmers S. \& Keene B. 2011. C-11: Characteristics of ARVC Boxers with sudden death. ACVIM Forum Research Abstracts Program. Denver, Colorado. American College of Veterinary Internal Medicine. (Resume)

Meurs K.M., Spier A.W., Miller M.W., Lehmkuhl L. \& Towbin J.A. 1999. Familial ventricular arrhythmias in boxers. J. Vet. Intern. Med. 13(5):437-439. <http:// dx.doi.org/10.1111/j.1939-1676.1999.tb01460.x> <PMid:10499727>

Montano N., Ruscone T.G., Porta A., Lombardi F., Pagani M. \& Malliani A. 1994. Power spectrum analysis of heart rate variability to assess the changes in sympathovagal balance during graded orthostatic tilt. Circulation 90(4):18261831. <http://dx.doi.org/10.1161/01.CIR.90.4.1826><PMid:7923668>

Mõtsküla P.F., Linney C., Palermo V., Connolly D.J., French A., Dukes McEwan J. \& Fuentes V.L. 2013. Prognostic value of 24-hour ambulatory ECG (Holter) monitoring in Boxer dogs. J. Vet. Intern. Med. 27(4):904-912.<http://dx.doi. org/10.1111/jvim.12107><PMid:23679064>

Obias-Manno D. \& Wijetunga M. 2004. Risk stratification and primary prevention of sudden cardiac death: sudden death prevention. AACN Clin. Issues 15(3):404-418. <http://dx.doi.org/10.1097/00044067-200407000-00008> $<$ PMid:15475814>

Palermo V., Stafford Johnson M.J., Sala E., Brambilla P.G. \& Martin M.W. 2011. Cardiomyopathy in Boxer dogs: a retrospective study of the clinical presentation, diagnostic findings and survival. J. Vet. Cardiol. 13(1):45-55. <http://dx.doi. org/10.1016/j.jvc.2010.06.005><PMid:21306968>

Rhee K.H., Jung J.Y., Rhee K.S., Kim H.S., Chae J.K., Kim W.H. \& Ko J.K. 2006. Tachycardiomyopathy induced by ventricular premature complexes: Complete recovery after radiofrequency catheter ablation. Korean J. Intern. Med. 21(3):213217. <http://dx.doi.org/10.3904/kjim.2006.21.3.213><PMid:17017676>

Sheldon S.H., Gard J.J. \& Asirvatham S.J. 2010. Premature ventricular contractions and non-sustained ventricular tachycardia: association with sudden cardiac death, risk stratification, and management strategies. Indian Pacing Electrophysiol. J. 10(8):357-371. <PMid:20811538>

Shiraishi H., Ishibashi K., Urao N., Tsukamoto M., Hyogo M., Keira N., Hirasaki S., Shirayama T. \& Nakagawa M. 2002. A case of cardiomyopathy induced by premature ventricular complexes. Circulation J. 66(11):1065-1067. <http:// dx.doi.org/10.1253/circj.66.1065><PMid:12419942>

Spier A.W. \& Meurs K.M. 2004a. Evaluation of spontaneous variability in the frequency of ventricular arrhythmias in Boxers with arrhythmogenic right ventricular cardiomyopathy. J. Am. Vet. Med. Assoc. 224(4):538-541.<http:// dx.doi.org/10.2460/javma.2004.224.538><PMid:14989546>

Spier A.W. \& Meurs K.M. 2004b. Assessment of heart rate variability in Boxers with arrhythmogenic right ventricular cardiomyopathy. J. Am. Vet. Med. Assoc. 224(4):534-537. <http://dx.doi.org/10.2460/javma.2004.224.534> $<$ PMid:14989545>

Stein P.K. \& Kleiger R.E. 1999. Insights from the study of heart rate variability. Ann. Rev. Med. 50:249-261. <http://dx.doi.org/10.1146/annurev.med.50.1.249> <PMid:10073276>

Takemoto M., Yoshimura H., Ohba Y., Matsumoto Y., Yamamoto U., Mohri M., Yamamoto H. \& Origuchi H. 2005. Radiofrequency catheter ablation of premature ventricular complexes from right ventricular outflow tract improves left ventricular dilation and clinical status in patients without structural heart disease.J. Am. Coll. Cardiol. 45(8):1259-1265. <http://dx.doi.org/10.1016/j. jacc.2004.12.073><PMid:15837259>

Viskin S., Rosso R., Rogowski O. \& Belhassen B. 2005. The "short-coupled" variant of right ventricular outflow ventricular tachycardia: A not-so-benign form of benign ventricular tachycardia? J. Cardiovasc. Electrophysiol. 16(8):912-916. <http://dx.doi.org/10.1111/j.1540-8167.2005.50040.x><PMid:16101636>

Zacché E., Assumpção T.C.A., Corsini T.B. \& Camacho A.A 2017. Time domain heart rate variability in Boxer dogs with arrhythmogenic right ventricular cardiomyopathy. Ciência Rural 47(5):1-6. <http://dx.doi.org/10.1590/01038478cr20160740> 